\title{
A Mobile App and Dashboard for Early Detection of Infectious Disease Outbreaks: Development Study
}

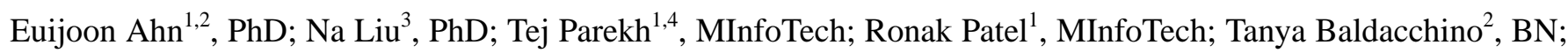
Tracy Mullavey ${ }^{2}, \mathrm{BN}$; Amanda Robinson ${ }^{5}$, BN; Jinman Kim ${ }^{1,2}, \mathrm{PhD}$

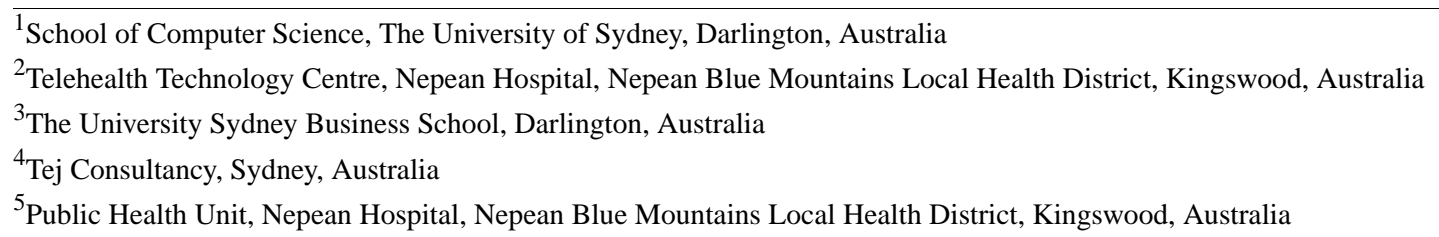

Corresponding Author:

Jinman Kim, PhD

School of Computer Science

The University of Sydney

Rm 340, Level 3, J12, 1 Cleveland St

Darlington, 2006

Australia

Phone: 61290369804

Email: jinman.kim@sydney.edu.au

\section{Abstract}

Background: Outbreaks of infectious diseases pose great risks, including hospitalization and death, to public health. Therefore, improving the management of outbreaks is important for preventing widespread infection and mitigating associated risks. Mobile health technology provides new capabilities that can help better capture, monitor, and manage infectious diseases, including the ability to quickly identify potential outbreaks.

Objective: This study aims to develop a new infectious disease surveillance (IDS) system comprising a mobile app for accurate data capturing and dashboard for better health care planning and decision making.

Methods: We developed the IDS system using a 2-pronged approach: a literature review on available and similar disease surveillance systems to understand the fundamental requirements and face-to-face interviews to collect specific user requirements from the local public health unit team at the Nepean Hospital, Nepean Blue Mountains Local Health District, New South Wales, Australia.

Results: We identified 3 fundamental requirements when designing an electronic IDS system, which are the ability to capture and report outbreak data accurately, completely, and in a timely fashion. We then developed our IDS system based on the workflow, scope, and specific requirements of the public health unit team. We also produced detailed design and requirement guidelines. In our system, the outbreak data are captured and sent from anywhere using a mobile device or a desktop PC (web interface). The data are processed using a client-server architecture and, therefore, can be analyzed in real time. Our dashboard is designed to provide a daily, weekly, monthly, and historical summary of outbreak information, which can be potentially used to develop a future intervention plan. Specific information about certain outbreaks can also be visualized interactively to understand the unique characteristics of emerging infectious diseases.

Conclusions: We demonstrated the design and development of our IDS system. We suggest that the use of a mobile app and dashboard will simplify the overall data collection, reporting, and analysis processes, thereby improving the public health responses and providing accurate registration of outbreak information. Accurate data reporting and collection are a major step forward in creating a better intervention plan for future outbreaks of infectious diseases.

(JMIR Public Health Surveill 2021;7(3):e14837) doi: 10.2196/14837

\section{KEYWORDS}

public health; infectious disease reporting; mobile app; disease notification; mobile phone 


\section{Introduction}

Outbreaks of infectious diseases, such as gastroenteritis, measles, influenza, and COVID-19, pose great risks, including hospitalization and death, to public health. Outbreaks have been directly associated with increased utilization of health care resources and negative social impacts [1,2]. Therefore, improving the management of these outbreaks is important for preventing widespread infection and mitigating associated risks. A core strategy to minimize the risk posed by widespread infectious diseases is the development of a surveillance system to quickly identify potential outbreaks as early as possible accurately, such that an effective intervention plan can be implemented before the substantial costs associated with the spread of diseases have been incurred.

Many infectious disease surveillance (IDS) systems have been developed to quickly collect, interpret, and respond to outbreaks. Organizations such as the US Centers for Disease Control and Prevention [3], Germany's SurvNet@RKI [4], and Australia's Health Victoria [5] have established digital and web-based disease notification systems. These systems are beneficial for timely reporting of disease outbreaks between distributed sites (often dispersed geographical locations) such as hospitals or community facilities (eg, aged care and childcare centers) and local public health units (PHUs). However, each system has been developed to satisfy particular needs (eg, specific to certain diseases [6] or patients only) and is thus limited in its applicability to a wider domain. Meanwhile, local health authorities in many countries still rely on conventional manual paper forms and communicate them via fax or email (eg, New South Wales [NSW] Ministry of Health [7]). Reporting in such a way between geographically dispersed sites is susceptible to lost, incomplete, and incorrect information [8]. This is problematic because of the increased public health costs associated with infectious diseases.
Mobile health (mHealth) technology is an emerging concept that uses mobile devices coupled with wireless technology for health care purposes [9-11]. It has gained great popularity in recent years and has been used in various clinical environments. Communication between clinicians and hospitals has been improved greatly using push alert and automatic notification (eg, paging) features [12]. In addition, a number of innovative mobile apps have been developed, such as remote patient monitoring systems [13] and orthopedic decision support apps [14]. With continued innovation in mHealth technologies, dashboards have also been introduced to summarize and integrate key information into a visual display for better decision making [15-17]. Clinical dashboards are generally designed to improve the quality of care by measuring performance metrics such as the doctor-to-bed ratio, hospital infection rates, and mortality ratios [15]. These data are then shared among clinicians in real time to react to patient needs as well as to efficiently capture and understand underlying patterns and trends.

Limited research has been conducted to investigate the use of mHealth technology coupled with dashboards to improve the management of the outbreak of infectious diseases. In this paper, we propose a new IDS system that accurately captures outbreak data using a mobile app and analyzes them by visualizing interactively using a dashboard. We developed our system using a 2-pronged approach; we firstly carried out a comprehensive literature review to understand the initial fundamental requirements of existing IDS systems and then conducted iterative face-to-face interviews to understand the context of use and collect user requirements. A flowchart of our 2-pronged approach is shown in Figure 1. We suggest that the use of mHealth technology and dashboard can improve the management of outbreaks between distributed sites and identify new opportunities for better health outcomes and planning. 
Figure 1. Flowchart of our 2-pronged approach. IDS: infectious disease surveillance.

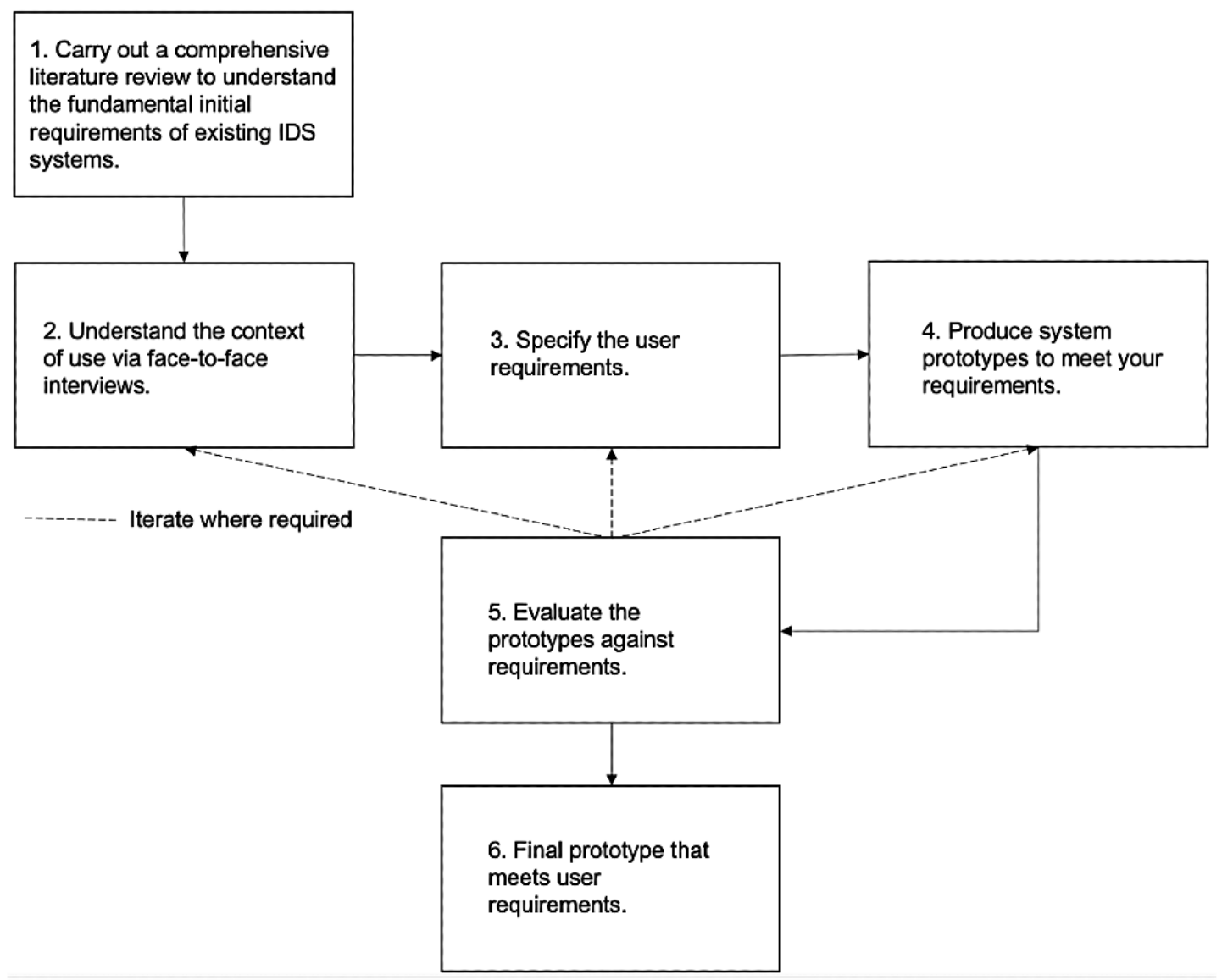

\section{Methods}

\section{Study Site and Setting}

This study was conducted at Nepean Blue Mountains Local Health District (NBMLHD), a Nepean hospital in NSW, Australia. NBMLHD covers both urban and semirural areas, covering approximately $9179 \mathrm{~km}^{2}$. The estimated resident population of NBMLHD in 2017 was 381,704 and is projected to increase by $30 \%$ by 2036 . The PHU at NBMLHD identifies and prevents or minimizes public health risks to the communities by working with local general practitioners, community health workers, schools and childcare centers, and aged care facilities.

All health facilities (eg, childcare centers and aged care facilities) in NBMLHD (and also across the NSW state) currently use a paper-based form to report outbreaks to local PHU teams, which is error prone and time consuming. The increasing populations along with large covering areas of the district will introduce new and unique challenges in the management of infectious disease outbreaks.

\section{Identification of Fundamental Requirements of the IDS System Through a Literature Review}

We conducted a literature review on existing IDS systems to analyze and define the overall scopes and fundamental requirements of our system, following the PRISMA-P (Preferred Reporting Items for Systematic Reviews and Meta-analyses Protocols) guidelines [18]. We also analyzed the design trends and incorporated the relevant technologies into our system, with a focus on studies that used mobile devices and dashboard systems.

We conducted a systematic search of published papers from the following scientific databases: PubMed and Web of Science. We searched the papers published in the last 15 years from 2004 , concerning infectious disease reporting and analysis using mHealth technologies. The search terms used were "infectious" AND "disease" AND "surveillance" AND "smartphone" OR "smartphone application" OR "mobile app" OR "mobile phones" OR “dashboard” OR “mHealth.” Figure 2 provides an overview of the study selection process.

The inclusion criteria were as follows: (1) infectious disease reporting systems must have been designed to use an electronic device (mobile phone, tablet, or personal computer) and (2) reporting was in the form of a specific app or website. We excluded papers that described the use of mobile-based systems for noninfectious diseases. Review papers were excluded. Only papers published in English were included. 
Figure 2. Flowchart of paper selections. mHealth: mobile health.

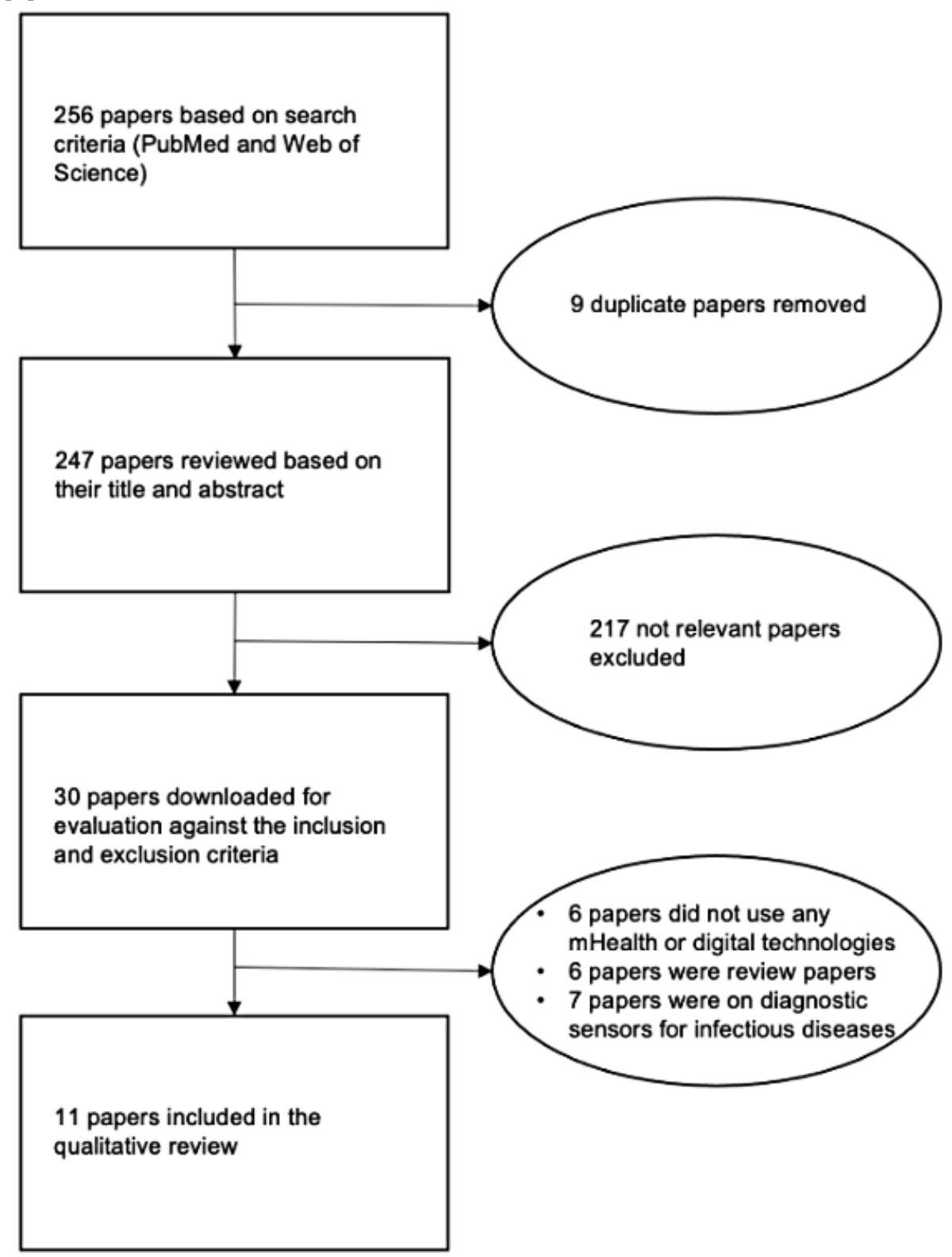

\section{Identification of Specific User Requirements of the IDS System Through Interviews}

Face-to-face interviews were conducted to collect the user requirements of our IDS system. Multiple interviews were carried out iteratively until we had a comprehensive understanding of user requirements. The participants included public health nurses from the local PHU team and telehealth providers from the NBMLHD. The interviews were conducted by experienced researchers, including project coordinators and software developers. First, we identified different types of end users and their corresponding roles. We then investigated and defined specific workflows and use case scenarios of our system. Our study did not require any patient involvement, as ethical approval or informed consent was not needed.

\section{User Interface Design and Agile Development}

Agile development uses an interactive system framework that aims to provide a good user experience. The initial user interfaces of the system were designed based on the user requirements and the understanding of the context of use. The software developers and health care team were in constant communication, discussing and enhancing the contents and user interfaces of the system. We developed a functional mobile app and dashboard prototype that was used to collect further feedback from users.

\section{Results}

\section{Phase 1: Literature Review of the State of the Art}

Our initial search identified 256 papers using the search criteria. We removed 9 duplicate papers and screened the remaining 247 papers based on their titles and abstracts. We then downloaded 30 relevant papers and examined them based on the inclusion and exclusion criteria. A total of 11 relevant papers were selected for qualitative review.

The papers described new digital technologies for better detection of, reporting on, and response to the outbreak of the diseases. A summary of our literature review of the existing 
IDS systems is shown in Table 1. Through analyzing the common and central aims of selected studies, we have identified 3 fundamental requirements for infectious disease reporting systems, which is the ability to capture and report outbreak data accurately, completely, and in a timely fashion [19-25]. Fundamental requirements were also used as the basis for identifying subsequent specific user requirements.

The ability to accurately capture and report data, such as symptoms and age, is important to create an optimal disease-specific intervention plan [21,26,27]. It is also crucial to identify and understand the unique characteristics of certain diseases; some diseases have a higher number of reported cases, but only a few patients have serious illnesses (eg, measles). Another electronic reporting system was used in Ireland to reduce the underreporting of notifiable diseases [28]. Underreporting has been associated with a number of factors, including clinicians' lack of time and motivation and the use of complicated and inconsistent paper forms. The electronic system, which was consistent and user friendly, created an environment where clinicians could better engage in reporting and understand their notification obligations [21,25,29]. An interactive data visualization technique (eg, web dashboard) was also used to understand the unique characteristics of certain infectious diseases, thereby improving the accuracy and completeness of outbreak reporting [27]. Kamadjeu et al [30] developed an electronic dashboard for the poliovirus outbreak response in Somalia. The dashboard captured complete outbreak data and was able to improve the daily analysis and sharing of outbreak information between different stakeholders, such as outbreak response managers and immunization partners located in various areas.

The internet-based reporting system OSIRIS was introduced in the Netherlands to reduce delays in receiving outbreak data and improve the completeness of the data [20]. The system was able to reduce the delay from 10 days to 1 day and had a higher completeness of data with over $10 \%$ improvements compared with traditional paper-based approaches. Similarly, Angues et al [21] used a mobile-based data collection platform and real-time cloud-based storage technology to reduce delayed recognition and intervention. Fahnrich et al [23] also developed a mobile-based system that can efficiently and promptly control Ebola in West Africa. 
Table 1. The descriptions of existing infectious disease surveillance systems found from our literature review.

\begin{tabular}{|c|c|c|c|c|}
\hline Study & $\begin{array}{l}\text { Infectious disease } \\
\text { addressed }\end{array}$ & $\begin{array}{l}\text { Description of } \\
\text { main aims or fea- } \\
\text { tures }\end{array}$ & Main outcomes reported & $\begin{array}{l}\text { Fundamental re- } \\
\text { quirements }\end{array}$ \\
\hline $\begin{array}{l}\text { Angues et al } 2018 \\
{[21]}\end{array}$ & Nodding syndrome & $\begin{array}{l}\text { To reduce delays } \\
\text { in receiving out- } \\
\text { break data from ru- } \\
\text { ral regions in } \\
\text { Uganda }\end{array}$ & $\begin{array}{l}\text { The primary outcome measure was whether the real-time mobile- } \\
\text { based system can improve the timeliness in reporting outbreak } \\
\text { data. The system was able to accurately capture the data and reduce } \\
\text { the delayed recognition and intervention. The system also created } \\
\text { an environment where clinicians can better engage with the report- } \\
\text { ing and understand their notification obligations. }\end{array}$ & $\begin{array}{l}\text { Accuracy, com- } \\
\text { pleteness, and } \\
\text { timeliness }\end{array}$ \\
\hline $\begin{array}{l}\text { Severi et al } 2014 \\
{[22]}\end{array}$ & $\begin{array}{l}\text { Food poisoning, } \\
\text { chickenpox, } \mathrm{Q} \\
\text { fever, etc }\end{array}$ & $\begin{array}{l}\text { To improve sensi- } \\
\text { tivity and timeli- } \\
\text { ness of infectious } \\
\text { disease data }\end{array}$ & $\begin{array}{l}\text { An event-based surveillance system was developed. The reports } \\
\text { from the system were timely and had complete information. }\end{array}$ & $\begin{array}{l}\text { Timeliness and } \\
\text { completeness }\end{array}$ \\
\hline $\begin{array}{l}\text { Fahnrich et al } 2015 \\
{[23]}\end{array}$ & Ebola & $\begin{array}{l}\text { To achieve effi- } \\
\text { cient and timely } \\
\text { control of commu- } \\
\text { nicable Ebola in } \\
\text { West Africa }\end{array}$ & $\begin{array}{l}\text { A standard digital Ebola outbreak management system was devel- } \\
\text { oped. The system can handle big data in combination with its mo- } \\
\text { bile interface for bidirectional information exchange between dif- } \\
\text { ferent users. }\end{array}$ & Timeliness \\
\hline $\begin{array}{l}\text { Waarbeek et al } \\
2011[24]\end{array}$ & $\begin{array}{l}\text { Hepatitis, A, B, } \\
\text { and C, etc }\end{array}$ & $\begin{array}{l}\text { To design a real- } \\
\text { time } \text { IDS }^{\mathrm{a}} \text { system } \\
\text { for cross-border } \\
\text { collaboration }\end{array}$ & $\begin{array}{l}\text { The collaborative disease protocols and risk assessments were } \\
\text { embedded into the IDS system that provides real-time surveillance } \\
\text { and geographical information. }\end{array}$ & Timeliness \\
\hline Blanchon [26] & $\begin{array}{l}\text { Acute diarrhea and } \\
\text { influenza-like ill- } \\
\text { ness }\end{array}$ & $\begin{array}{l}\text { To identify gaps in } \\
\text { the French Sen- } \\
\text { tinelles IDS system }\end{array}$ & $\begin{array}{l}\text { The main finding is that it is important to maintain a high level of } \\
\text { motivation and participation among physicians to improve the } \\
\text { completeness and accuracy of outbreak data. }\end{array}$ & $\begin{array}{l}\text { Accuracy and } \\
\text { completeness }\end{array}$ \\
\hline Yan et al 2013 [27] & $\begin{array}{l}\text { Symptoms such as } \\
\text { cough, sore throat, } \\
\text { and fever }\end{array}$ & $\begin{array}{l}\text { To design and pilot } \\
\text { implementation of } \\
\text { a syndromic } \\
\text { surveillance sys- } \\
\text { tem in rural China }\end{array}$ & $\begin{array}{l}\text { A new web-based syndromic surveillance system was developed, } \\
\text { which allows accurate and immediate reporting of syndromic data } \\
\text { and automated detection of abnormal disease clusters using inter- } \\
\text { active visualization (ie, dashboard). }\end{array}$ & $\begin{array}{l}\text { Accuracy, com- } \\
\text { pleteness, and } \\
\text { timeliness }\end{array}$ \\
\hline $\begin{array}{l}\text { Brabazon et al } \\
2015 \text { [28] }\end{array}$ & $\begin{array}{l}\text { Viral meningitis, } \\
\text { viral encephalitis, } \\
\text { bacterial meningi- } \\
\text { tis, malaria, etc }\end{array}$ & $\begin{array}{l}\text { To identify if there } \\
\text { was significant un- } \\
\text { derreporting of } \\
\text { hospitalized notifi- } \\
\text { able infectious dis- } \\
\text { eases in Ireland }\end{array}$ & $\begin{array}{l}\text { A new computerized IDS system was developed, which reduced } \\
\text { underreporting of outbreak data. }\end{array}$ & $\begin{array}{l}\text { Accuracy and } \\
\text { completeness }\end{array}$ \\
\hline $\begin{array}{l}\text { Karimuribo et al } \\
2017 \text { [29] }\end{array}$ & Any symptoms & $\begin{array}{l}\text { To design a partici- } \\
\text { patory disease } \\
\text { surveillance sys- } \\
\text { tem for communi- } \\
\text { ty-based health re- } \\
\text { porters in East and } \\
\text { Southern Africa }\end{array}$ & $\begin{array}{l}\text { A mobile-based disease surveillance system was developed, which } \\
\text { improved the engagement of people in their own communities in } \\
\text { the detection of infectious human and animal disease threats. }\end{array}$ & Completeness \\
\hline
\end{tabular}




\begin{tabular}{|c|c|c|c|c|}
\hline Study & $\begin{array}{l}\text { Infectious disease } \\
\text { addressed }\end{array}$ & $\begin{array}{l}\text { Description of } \\
\text { main aims or fea- } \\
\text { tures }\end{array}$ & Main outcomes reported & $\begin{array}{l}\text { Fundamental re- } \\
\text { quirements }\end{array}$ \\
\hline $\begin{array}{l}\text { Kamadjeu et al } \\
2017 \text { [30] }\end{array}$ & Poliovirus & $\begin{array}{l}\text { To design and im- } \\
\text { plement an elec- } \\
\text { tronic dashboard } \\
\text { for polio outbreak } \\
\text { response manage- } \\
\text { ment }\end{array}$ & $\begin{array}{l}\text { The Somalia Polio Room Dashboard was developed; it integrates } \\
\text { various outbreak and surveillance response data sources into rich } \\
\text { graphical interfaces. The dashboard was able to reduce the need } \\
\text { for daily analysis and sharing of outbreak information between } \\
\text { different stakeholders. }\end{array}$ & Accuracy \\
\hline
\end{tabular}

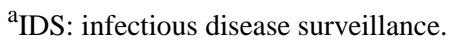

\section{Phase 2: User Research and User Requirements}

The results of the literature reviews allowed us to create a list of appropriate questions to be asked for subsequent face-to-face interviews. Some of the questions were designed to derive answers that could potentially help improve the ability to capture and report the outbreak data accurately, completely, and in a timely fashion. We conducted several interviews with 2 public health nurses and 1 clinical doctor from the PHU team to understand the overall workflow of how outbreak data were communicated between community facilities and the PHU team. The list of interview questions and their corresponding answers are presented in Table 2. Testimony from users and experts was used to help developers better understand user requirements.

Table 2. The list of interview questions and corresponding answers to understand the context of use.

\begin{tabular}{llll}
\hline $\begin{array}{l}\text { Question ID } \\
\text { number }\end{array}$ & Question themes & Interview questions & Answers (user requirements) \\
\hline 1 & $\begin{array}{l}\text { Data security and } \\
\text { user access }\end{array}$ & $\begin{array}{l}\text { Can anyone use the mobile } \\
\text { app? }\end{array}$ & $\begin{array}{l}\text { No; only registered clinicians should use the mobile } \\
\text { app and the registration should be limited. }\end{array}$ \\
2 & Data capturing & $\begin{array}{l}\text { What are the required fields } \\
\text { when entering outbreak data } \\
\text { for a patient? }\end{array}$ & $\begin{array}{l}\text { Patient name, date of birth, sex saccination details, } \\
\text { symptoms and laboratory testing details, date of } \\
\text { onset of symptoms, and date of last symptoms are } \\
\text { required. }\end{array}$
\end{tabular}

$3 \quad$ Data capturing (accuracy and completeness)

Data update and review (timeliness)

Data update and review (timeliness) racy and completeness)

Data report

Data report
What are the common errors when entering outbreak data?

What are the most important fields (ie, mandatory fields) that need to be captured?

How do you update and track the details of certain outbreak data?

How often do you need to check the status of the outbreak or patients?

What are the key fields that allow you to search and identify right patient?

What are the fields of patients that you would like to see on the web dashboard? Would those fields be able to help you identify right information?

What are the most important reports that you would like to see when you $\log$ in to the web dashboard?
Sources

This was a common answer among all interviewees.

One of the public health nurses said some of the data such as laboratory testing details might not be available at the initial stage of the outbreak.

Patient names, case number, symptoms, symptoms onset date, sex, date of birth, disease type, and occupancy need to be at least captured.

Existing patient outbreak data must be reviewed and monitored to identify any changes in symptoms.

This was a common answer among all interviewees.

This was a common answer among all interviewees.

On the outbreak of infectious disease in a particular facility, the PHU ${ }^{\mathrm{a}}$ nurses need to contact the facility every day to check the status of the outbreak and conditions of patients.

The symptoms of patients and symptoms onset date are often inconsistent. This is because there are multiple nursing staff at the facilities recording data every day, and there can be errors during handover.

Facility name, age, and patient name.

This was a common answer among all interviewees.

This was a common answer among all interviewees.

This was a common answer among all interviewees.

We felt that the most important field to see would be patient name, facility name, hospitalized (yes or no), deceased (yes or no), treatment or prophylaxis type, and pathogen (influenza or gastro). We thought these would be the most important to see first as long as full patient details can be provided from expanded page view if needed.

It is important to view the weekly total number of patients reported under each infectious disease for the past 6 months.
This was a common answer among all interviewees.

${ }^{\mathrm{a} P H U}$ : public health unit. 


\section{Phase 3: Extraction of Function Requirements}

The results of the user interviews were then used to formulate functional requirements. A list of functional requirements is presented in Table 3 . The use case diagram of our mobile app is shown in Figure 3. The diagram represents the main functionalities of the mobile app: data capturing and notification.

Table 3. The list of functional requirements formulated based on the outcomes of interviews.

\begin{tabular}{|c|c|c|}
\hline $\begin{array}{l}\text { Question ID } \\
\text { number (consis- } \\
\text { tent with Table 2) }\end{array}$ & Function type & Functional requirements \\
\hline 1 & $\begin{array}{l}\text { User verification for } \\
\text { new registration }\end{array}$ & $\begin{array}{l}\text { Send a request to the web server to verify the verification passcode entered by the user. If the passcode } \\
\text { is validated, then the user can be registered; otherwise, display an error message. }\end{array}$ \\
\hline 2 & Data capturing & $\begin{array}{l}\text { Patient name, date of birth, sex, vaccination details, symptoms and laboratory testing details, date of } \\
\text { onset of symptoms, and date of last symptoms. Validate the fields against the required fields. Show an } \\
\text { error message if the user has not entered the mandatory field. }\end{array}$ \\
\hline 3 & Data mandatory fields & $\begin{array}{l}\text { Create mandatory fields on patient names, case number, symptoms, symptoms onset date, sex, date of } \\
\text { birth, disease type, and occupancy. }\end{array}$ \\
\hline 4 & Data update & $\begin{array}{l}\text { Existing patient information can be easily retrieved, and users should be able to easily submit a new report } \\
\text { based on previous outbreak data. }\end{array}$ \\
\hline 5 & $\begin{array}{l}\text { User alert for regular } \\
\text { data submission }\end{array}$ & Create a push alert to inform users to regularly submit outbreak data for individual patient. \\
\hline 6 & $\begin{array}{l}\text { User error reducing } \\
\text { functions }\end{array}$ & $\begin{array}{l}\text { Most recently reported data can be prefilled, and the symptom onset date should not be editable once } \\
\text { submitted. }\end{array}$ \\
\hline 7 & $\begin{array}{l}\text { User convenience func- } \\
\text { tions }\end{array}$ & Create search bars for each field so that users can easily retrieve relevant information. \\
\hline 8 & User report & $\begin{array}{l}\text { Create an overview web page of selected infectious diseases and list all the patients in the table with the } \\
\text { columns showing patient name, facility name, hospitalized (yes or no), deceased (yes or no), and treatment } \\
\text { or prophylaxis type. Create an individual page to show all the details of the case reported when clicked } \\
\text { by users. }\end{array}$ \\
\hline 9 & User report & $\begin{array}{l}\text { Create a table that displays the number of cases reported for each infectious disease during the outbreak; } \\
\text { create landing pages that contain a 2-dimensional graph if there has been increase or decrease in the } \\
\text { number of cases reported. }\end{array}$ \\
\hline
\end{tabular}


Figure 3. Use case diagram for the system (mobile app).

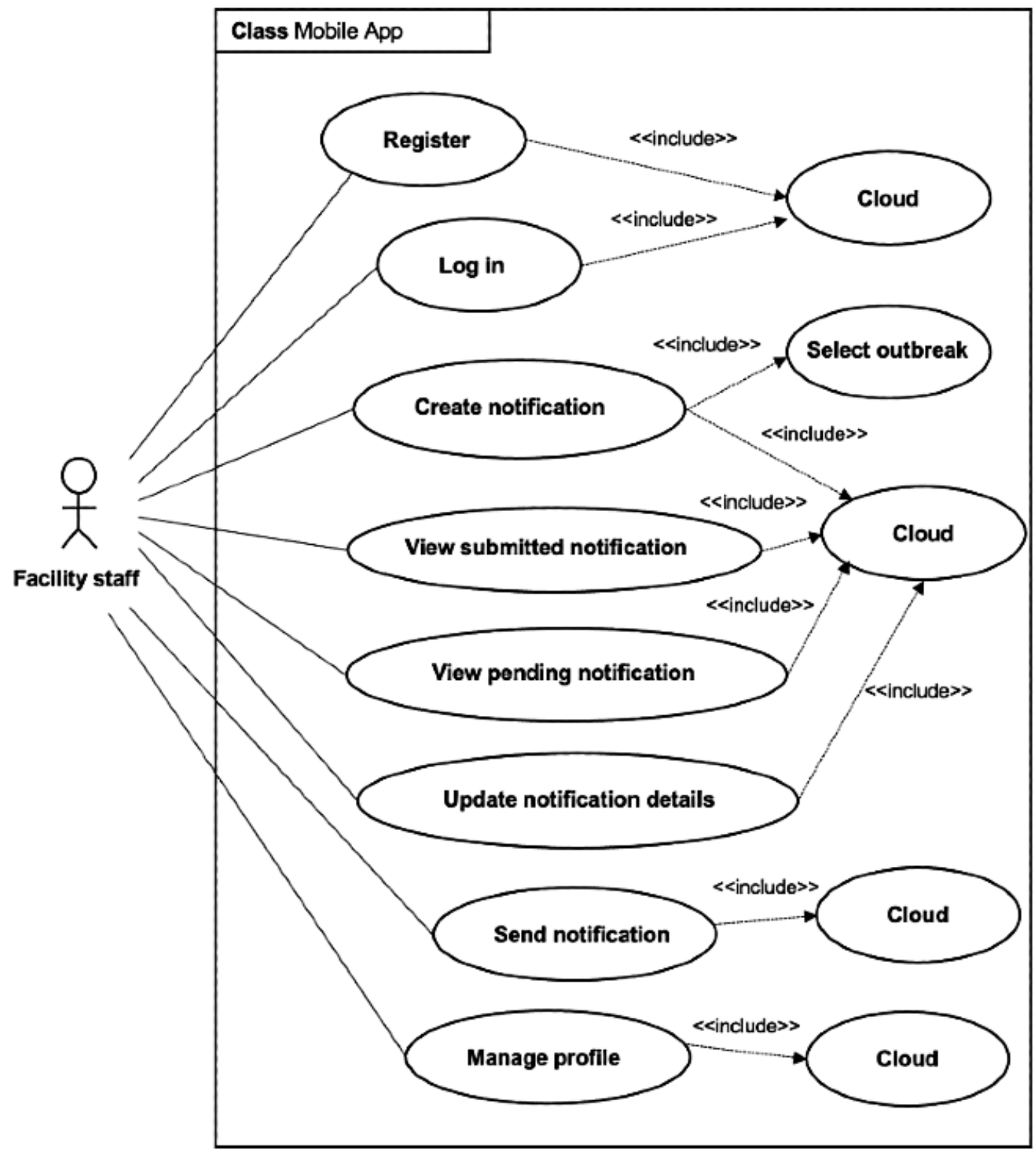

\section{Phase 4: Prototype Building and Iteration}

On the basis of communication between clinicians and development teams, we developed an app and dashboard prototype. The app and dashboard were presented back to clinicians for further feedback, and we identified new user requirements that were not found in phase 1 . A list of new requirements identified is shown in Table 4. We updated and improved the prototype system iteratively based on the feedback from 3 clinicians from the PHU team and 2 clinicians from the telehealth team over the period between January 2017 and December 2017. A description of the main functionalities of our prototype is presented in Table 5 .

Table 4. The list of changes to functional requirements based on the exposure of prototypes to clinicians.

\begin{tabular}{ll}
\hline Question ID number & New functional requirements \\
\hline 8 & - $\quad \begin{array}{l}\text { Create a separate report designed for individual facility; summary of current active outbreaks within a facility. The data } \\
\text { can also be visualized interactively, showing historical or specific details of an outbreak. } \\
\text { Create a summary of current active outbreaks across the whole local health district. Specific outbreak details of certain } \\
\text { facilities can also be visualized. }\end{array}$ \\
- The data need to be better presented by highlighting important metrics such as the number of reported cases and patient \\
- An automatic email notification to the PHU ${ }^{\mathrm{a}}$ team is required when there are any new reported outbreaks.
\end{tabular}

${ }^{\mathrm{a}} \mathrm{PHU}$ : public health unit. 
Table 5. The description of the main functionalities of our prototype.

\begin{tabular}{lll}
\hline Type & Main functionalities \\
\hline Function 1: Data capturing & - $\quad \begin{array}{l}\text { Outbreak details need to be entered, edited, and submitted using a mobile app or desktop PC (web interface) } \\
\text { without geographical restrictions (within registered facilities managed by local PHU }{ }^{\text {a }} \text { ). }\end{array}$ \\
- $\begin{array}{l}\text { Clinical information collected includes patient name, date of birth, sex, vaccination details, symptoms and labora- } \\
\text { tory testing details, date of onset of symptoms, and date of last symptoms. }\end{array}$ \\
$\begin{array}{l}\text { Enforce correct and mandatory data entry (eg, facility care type and symptoms onset date). } \\
\text { Function 2: Outbreak notifi- } \\
\text { cation }\end{array}$
\end{tabular}
to the local PHU team.

Function 3: Data report for facilities

Function 4: Data report for PHU

Function 5: Data storage
- Summary of current active outbreaks within a facility. The data can also be visualized interactively, showing historical or specific details of an outbreak.

- Summary of current active outbreaks across the whole local health district. Specific outbreak details of certain facilities can be also visualized.

- The data need to be processed and stored in a secure server.

${ }^{\mathrm{a}} \mathrm{PHU}$ : public health unit.

\section{System Overview}

Figure 4 shows an overview of our proposed system. Our system consists of a mobile app, a cloud server, and a dashboard. On the outbreak of an infectious disease in a facility, staff from the facility capture the patient data, including symptoms and vaccination details, using a mobile device or desktop PC (web interface) and send them to the cloud server. The data are then processed and displayed on the dashboard in real time. The cloud server automatically notifies PHU nurses by sending an email. The PHU nurses then use the web dashboard to receive and analyze the outbreak data.

Figure 4. Overview of our proposed system. Data analysis and dashboard. API: application programming interface; PHU: public health unit.

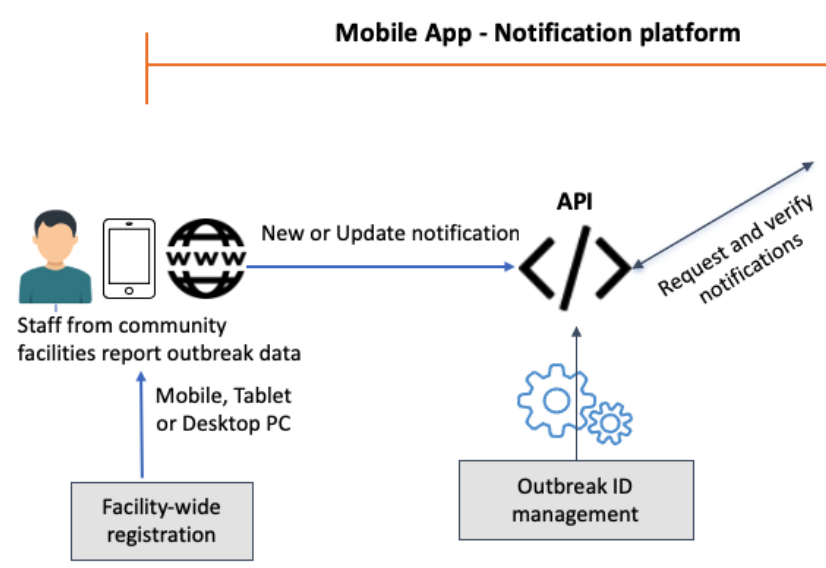

\section{Mobile App}

The mobile app was developed for both Android and iOS devices using a cross-platform app development framework. We specifically used a development platform called cross-compilation [31], which automatically transforms source code into platform-specific apps. We also developed a mobile web app so that it could be run in a standard web browser (Figure 5).

Users can create a new outbreak detail and add or edit the details of existing information, as shown in Figure 6 (function 1). During an outbreak of infectious diseases, it is important to monitor the symptoms of patients daily; therefore, our app

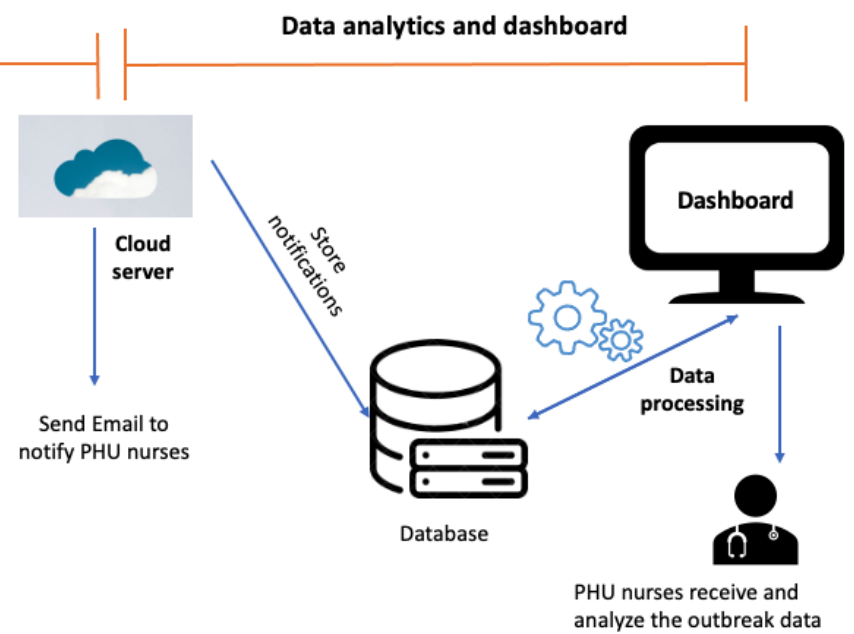

allows us to review the history of previous patient details of outbreaks. Our app then sends them to a cloud server using an application programming interface gateway. To prevent unauthorized data submissions, the app is only accessible to users with a preregistered verification passcode, which is controlled by the PHU. All data are encrypted and sent using a JavaScript Object Notation (JSON) Web Token (JWT), which can only be validated at the cloud server (function 5). Automatic email notification is also sent to the PHU once a new outbreak is reported (function 2). The accessibility and user registration of the app are controlled by the cloud server. We used the local cloud server, and the data were encrypted using JWTs to enforce the security of communication. 
Figure 5. A web version of our mobile app with a consistent user interface. Web technologies such as HTML 5, Cascading Style Sheet 3, and JavaScript were used.

\begin{tabular}{|c|c|c|c|c|c|c|c|}
\hline 000 & $<$ & $>$ & 回 & https://nidn.outbreak-notifier C & () & 屯 & $\gg$ \\
\hline$M$ & & & & Outbreak Notifier & & & + \\
\hline
\end{tabular}

\section{NSW Health Notification}

\section{Menu}

$+\quad$ New Notification

1 Notifications History

을 Manage Profile

D Reports

\section{Information}

\section{Key Definitions}

\section{$\square$ Guidelines}

Figure 6. Example screenshots of our mobile app.

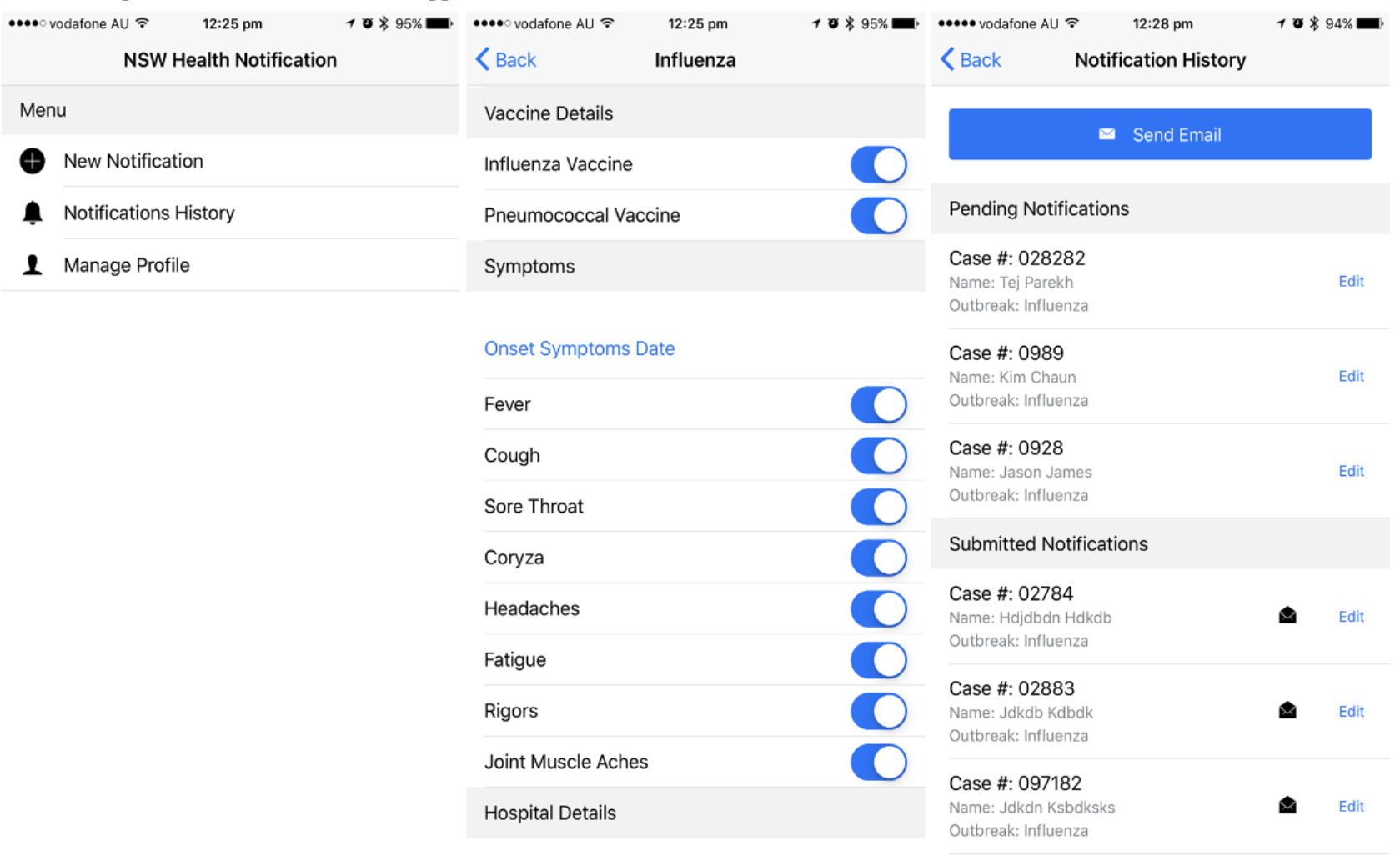




\section{Dashboard}

We developed a dashboard using an open-source Hypertext Preprocessor (PHP) Laravel framework. It provides rich built-in features, such as authentication, authorization, and a database management system. The use of the Laravel framework allowed us to iteratively develop our system and efficiently refine it based on the feedback received from the PHU team.

The dashboard displays outbreak data sent via our mobile app in real time (function 2). Figure 7 displays a quick summary of the key information (eg, facility name, room number, patient details, and vaccination details). Figure 8 shows a summary of current active outbreaks, providing daily, weekly, and monthly summaries of reported cases (functions 3 and 4). To present data that are visually intuitive, key information is color coded and graphical charts are also used. More specific and historical data of an outbreak can also be retrieved. Figure 9 shows the trend of the selected outbreak over multiple years.

To make our system more applicable to wider domains (eg, different states or countries), data attributes such as different types of infectious diseases, symptoms, and registered community facilities can be added, modified, and deleted through the dashboard.

Figure 7. Details of the reported cases of infectious diseases. The Hypertext Preprocessor (PHP) Laravel framework is a popular and standard development framework that follows a model view controller architecture pattern.

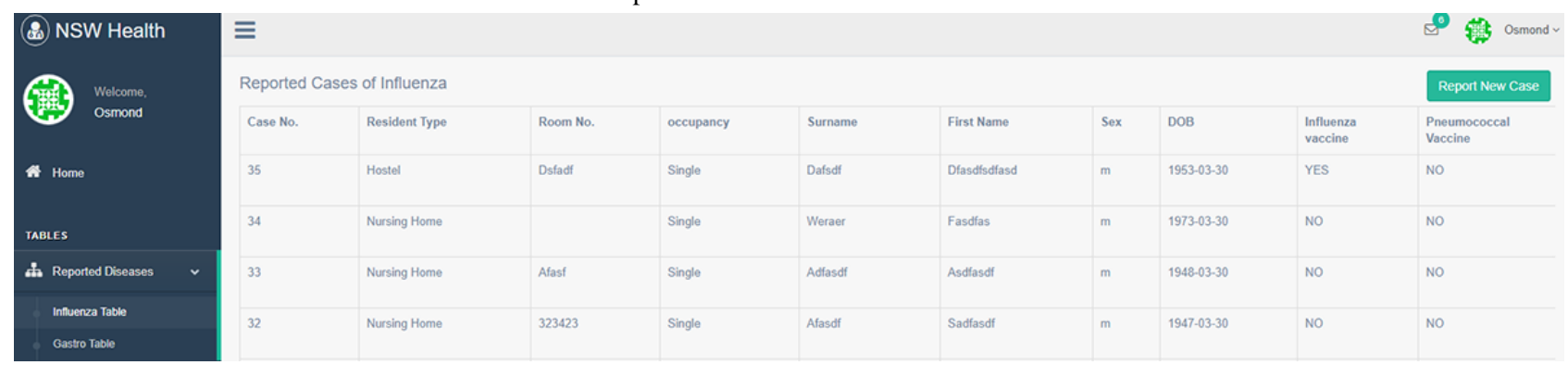

Figure 8. Daily, weekly, and monthly summary of current active outbreaks.

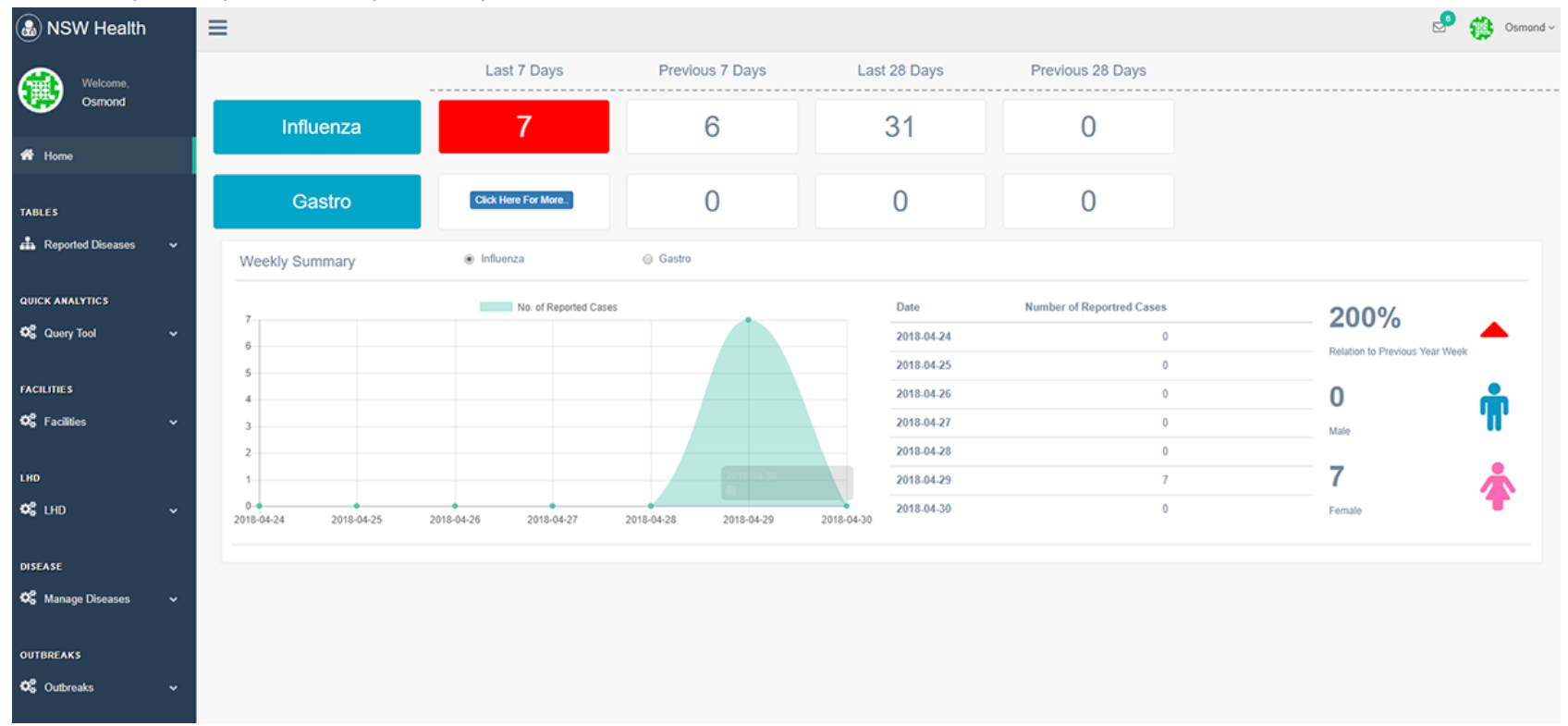


Figure 9. An historical summary of a specific outbreak.

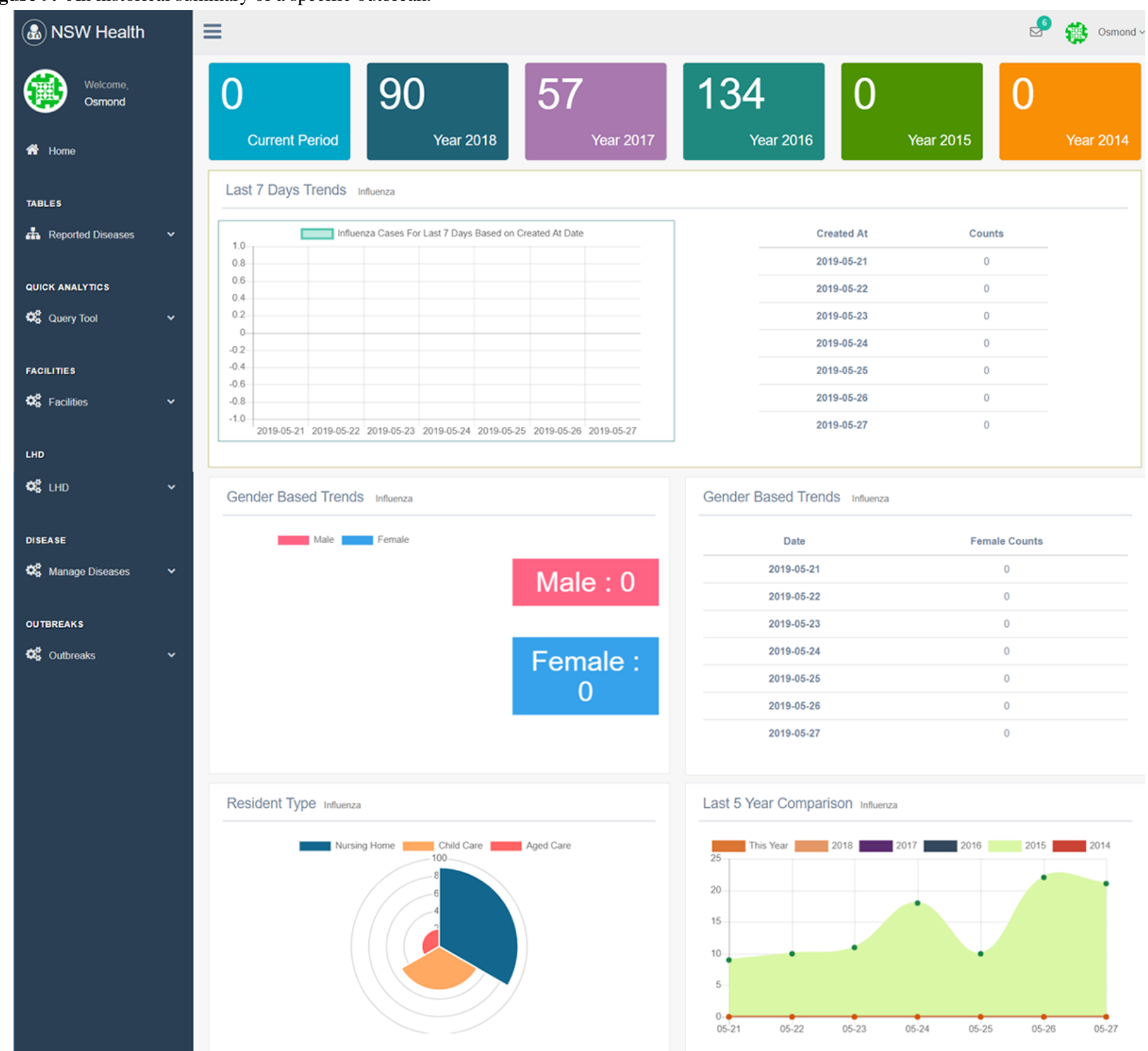

\section{Discussion}

\section{Principal Findings}

This study collected user requirements using a 2-pronged approach: a literature review and face-to-face interviews. We identified 3 fundamental requirements when designing an electronic IDS system through the literature review and developed a new IDS system using iterative face-to-face interviews. We also presented the development and implementation details of a new IDS system using mHealth technologies. Our study focused on the development of a generic mobile app or dashboard framework for capturing and reporting outbreak data, which is different from conventional existing works that are limited to addressing specific infectious diseases such as influenza [6,32-34] or patient cohorts [35].

With the portability of using a mobile device, outbreak data can be captured and sent from anywhere, and the use of the cross-platform framework further allows users to record the data with different types of devices (eg, mobile, tablet, and PC).
The data are transferred using a client-server architecture and, therefore, can be analyzed in real time. Our dashboard is designed to provide a daily, weekly, monthly, and historical summary of outbreak information, highlighting important metrics such as the number of reported cases, male-to-female ratio, and number of reported specific symptoms. Specific information about certain outbreaks can also be visualized interactively, which can help understand the unique characteristics of emerging infectious diseases. Some of the key feedback we received from the PHU were as follows: (1) ability to enforce correct and mandatory data entry (eg, facility care type and symptom onset date) and (2) identification of key metrics that need to be visualized in the dashboard. The capability to customize data attributes is important for adaptively refining the system for general applications.

We suggest that the use of a mobile app and dashboard will simplify the overall data collection, reporting, and analysis processes, thereby improving the public health responses and providing accurate registration of outbreak information, which can potentially reduce associated morbidity and mortality [8]. 
This can also improve communication and engagement between clinicians and community facilities, providing more accessible information and education about infectious diseases.

We will evaluate the effectiveness of our proposed system by piloting the system at local community facilities, such as aged care and childcare centers. Preimplementation and postimplementation surveys will be conducted. Our system has a few limitations. Although our PHU team had extensive clinical experience, the system was developed and refined based on feedback from a single hospital; expanding across multiple hospitals will help generalize overall scopes.

\section{Conclusions}

We suggest that accurate data reporting and collection, enabled by our system, are a major step forward in the early detection of a future outbreak of infectious diseases. With the availability of large-scale outbreak data, population-based analysis can be conducted to understand the overall characteristics of the outbreaks. This can potentially help prevent widespread infection and associated risks. Effective intervention plans can also be created based on the patterns identified and provided before the substantial avoidable spread of diseases has been incurred. Another key advantage of using large-scale data is the application of machine learning algorithms (eg, convolutional neural networks [36]) to predict infectious diseases. These predictive models can be derived and embedded in our notification system.

\section{Acknowledgments}

This research was supported by the Telehealth and Technology Center, Nepean Hospital, NBMLHD, NSW, Australia.

\section{Authors' Contributions}

EA, NL, TB, TM, AR, and JK were responsible for the conceptualization of this project. TP, RP, EA, and JK were responsible for developing the proposed system. All authors contributed to the preparation of this manuscript.

\section{Conflicts of Interest}

None declared.

\section{References}

1. Smith PW, Rusnak PG. Infection Prevention and Control in the Long-Term-Care Facility. Infection Control and Hospital Epidemiology 1997 Dec;18(12):831-849. [doi: 10.2307/30141342]

2. Montoya A, Mody L. Common infections in nursing homes: a review of current issues and challenges. Aging Health 2011 Dec;7(6):889-899. [doi: 10.2217/ahe.11.80]

3. Coates RJ, Jajosky RA, Stanbury M, Macdonald SC. Summary of Notifiable Noninfectious Conditions and Disease Outbreaks: Introduction to the Summary of Notifiable Noninfectious Conditions and Disease Outbreaks - United States. MMWR Morb. Mortal. Wkly. Rep 2015 Oct 23;62(54):1-4. [doi: 10.15585/mmwr.mm6254a1]

4. Faensen D, Claus H, Benzler J, Ammon A, Pfoch T, Breuer T, et al. SurvNet@ RKI--a multistate electronic reporting system for communicable diseases. Euro Surveill 2006;11(4):100-103. [Medline: 16645245]

5. Notifications procedures for infectious diseases. Victoria State Government. URL: https://www2.health.vic.gov.au/ public-health/infectious-diseases/notification-procedures [accessed 2021-02-11]

6. Iribarren SJ, Schnall R, Stone PW, Carballo-Diéguez A. Smartphone Applications to Support Tuberculosis Prevention and Treatment: Review and Evaluation. JMIR mHealth uHealth 2016 May 13;4(2):e25. [doi: 10.2196/mhealth.5022]

7. Disease notification - Infectious Diseases. NSW Ministry of Health. URL: http://www.health.nsw.gov.au/Infectious/Pages/ notification.aspx [accessed 2021-02-11]

8. Revere D, Hills RH, Dixon BE, Gibson PJ, Grannis SJ. Notifiable condition reporting practices: implications for public health agency participation in a health information exchange. BMC Public Health 2017 Mar 11;17(1). [doi: 10.1186/s12889-017-4156-4]

9. Onodera R, Sengoku S. Innovation process of mHealth: An overview of FDA-approved mobile medical applications. International Journal of Medical Informatics 2018 Oct;118:65-71. [doi: 10.1016/j.ijmedinf.2018.07.004]

10. Ventola CL. Mobile devices and apps for health care professionals: uses and benefits. P T 2014 May;39(5):356-364 [FREE Full text] [Medline: 24883008]

11. Al Ayubi SU, Pelletier A, Sunthara G, Gujral N, Mittal V, Bourgeois FC. A Mobile App Development Guideline for Hospital Settings: Maximizing the Use of and Minimizing the Security Risks of. JMIR mHealth uHealth 2016 May 11;4(2):e50. [doi: 10.2196/mhealth.4424]

12. Wu RC, Morra D, Quan S, Lai S, Zanjani S, Abrams H, et al. The use of smartphones for clinical communication on internal medicine wards. J. Hosp. Med 2010 Aug 05;5(9):553-559. [doi: 10.1002/jhm.775]

13. Liu N, Kim J, Jung Y, Arisy A, Nicdao MA, Mikaheal M, et al. Remote Monitoring Systems for Chronic Patients on Home Hemodialysis: Field Test of a Copresence-Enhanced Design. JMIR Hum Factors 2017 Aug 29;4(3):e21. [doi: 10.2196/humanfactors.7078] 
14. Franko OI. Smartphone apps for orthopaedic surgeons. Clin Orthop Relat Res 2011 Jul;469(7):2042-2048 [FREE Full text] [doi: 10.1007/s11999-011-1904-0] [Medline: 21547414]

15. Dowding D, Randell R, Gardner P, Fitzpatrick G, Dykes P, Favela J, et al. Dashboards for improving patient care: Review of the literature. International Journal of Medical Informatics 2015 Feb;84(2):87-100. [doi: 10.1016/j.ijmedinf.2014.10.001]

16. Wang Y, Kung L, Byrd TA. Big data analytics: Understanding its capabilities and potential benefits for healthcare organizations. Technological Forecasting and Social Change 2018 Jan;126:3-13. [doi: 10.1016/j.techfore.2015.12.019]

17. Zhang X, Gallagher K, Goh S. Bi Application: Dashboards for healthcare. AMCIS 2011 Proceedings - All Submissions 2011:442 [FREE Full text]

18. Moher D. Preferred Reporting Items for Systematic Reviews and Meta-Analyses: The PRISMA Statement. Ann Intern Med 2009 Aug 18;151(4):264. [doi: 10.7326/0003-4819-151-4-200908180-00135]

19. Milinovich GJ, Williams GM, Clements ACA, Hu W. Internet-based surveillance systems for monitoring emerging infectious diseases. The Lancet Infectious Diseases 2014 Feb;14(2):160-168. [doi: 10.1016/s1473-3099(13)70244-5]

20. Ward M, Brandsema P, van Straten E, Bosman A. Electronic reporting improves timeliness and completeness of infectious disease notification, The Netherlands, 2003. Euro Surveill 2005 Jan;10(1):7-8. [doi: 10.2807/esm.10.01.00513-en] [Medline: 29183539]

21. Valdes Angues R, Suits A, Palmer VS, Okot C, Okot RA, Atonywalo C, et al. A real-time medical cartography of epidemic disease (Nodding syndrome) using village-based lay mHealth reporters. PLoS Negl Trop Dis 2018 Jun 15;12(6):e0006588. [doi: 10.1371/journal.pntd.0006588]

22. Severi E, Kitching A, Crook P. Evaluation of the Health Protection Event-Based Surveillance for the London 2012 Olympic and Paralympic Games. Euro Surveill 2014 Jun 19;19(24):20832 [FREE Full text] [doi: 10.2807/1560-7917.es2014.19.24.20832] [Medline: 24970374]

23. Fähnrich C, Denecke K, Adeoye OO, Benzler J, Claus H, Kirchner G, et al. Surveillance and Outbreak Response Management System (SORMAS) to support the control of the Ebola virus disease outbreak in West Africa. Euro Surveill 2015 Mar 26;20(12):21071 [FREE Full text] [doi: 10.2807/1560-7917.es2015.20.12.21071] [Medline: 25846493]

24. ter Waarbeek H, Hoebe C, Freund H, Bochat V, Kara-Zaïtr C. Strengthening infectious disease surveillance in a Dutch-German crossborder area using a real-time information exchange system. J Bus Contin Emer Plan 2011 Jun;5(2):173-184. [Medline: 21835755]

25. Diwan V, Agnihotri D, Hulth A. Collecting syndromic surveillance data by mobile phone in rural India: implementation and feasibility. Global Health Action 2015 Apr 02;8(1):26608. [doi: 10.3402/gha.v8.26608]

26. Blanchon T. Web - based sentinel provider surveillance network in France. New Jersey: Wiley; 2013:418-425.

27. Yan W, Palm L, Lu X, Nie S, Xu B, Zhao Q, et al. ISS-An Electronic Syndromic Surveillance System for Infectious Disease in Rural China. PLoS ONE 2013 Apr 23;8(4):e62749. [doi: 10.1371/journal.pone.0062749]

28. Brabazon ED, Sheridan A, Finnegan P, Carton MW, Bedford D. Under-reporting of notifiable infectious disease hospitalizations: significant improvements in the Irish context. Epidemiol. Infect 2014 Jul 18;143(6):1166-1174. [doi: $10.1017 / \mathrm{s} 0950268814001733$ ]

29. Karimuribo ED, Mutagahywa E, Sindato C, Mboera L, Mwabukusi M, Kariuki Njenga M, et al. A Smartphone App (AfyaData) for Innovative One Health Disease Surveillance from Community to National Levels in Africa: Intervention in Disease Surveillance. JMIR Public Health Surveill 2017 Dec 18;3(4):e94. [doi: 10.2196/publichealth.7373]

30. Kamadjeu R, Gathenji C. Designing and implementing an electronic dashboard for disease outbreaks response - Case study of the 2013-2014 Somalia Polio outbreak response dashboard. Pan Afr Med J 2017;27. [doi: 10.11604/pamj.supp.2017.27.3.11062]

31. Hartmann G, Stead G, DeGani A. Cross-platform mobile development. Mobile Learning Environment, Cambridge 2011;16(9):158-171 [FREE Full text]

32. Chunara R, Goldstein E, Patterson-Lomba O, Brownstein JS. Estimating influenza attack rates in the United States using a participatory cohort. Sci Rep 2015 Apr 2;5(1). [doi: 10.1038/srep09540]

33. Santillana M, Nguyen AT, Dredze M, Paul MJ, Nsoesie EO, Brownstein JS. Combining Search, Social Media, and Traditional Data Sources to Improve Influenza Surveillance. PLoS Comput Biol 2015 Oct 29;11(10):e1004513. [doi: 10.1371/journal.pcbi.1004513]

34. Smolinski MS, Crawley AW, Baltrusaitis K, Chunara R, Olsen JM, Wójcik O, et al. Flu Near You: Crowdsourced Symptom Reporting Spanning 2 Influenza Seasons. Am J Public Health 2015 Oct;105(10):2124-2130. [doi: 10.2105/ajph.2015.302696]

35. Lawpoolsri S, Khamsiriwatchara A, Liulark W, Taweeseneepitch K, Sangvichean A, Thongprarong W, et al. Real-Time Monitoring of School Absenteeism to Enhance Disease Surveillance: A Pilot Study of a Mobile Electronic Reporting System. JMIR mHealth uHealth 2014 May 12;2(2):e22. [doi: 10.2196/mhealth.3114]

36. Chen M, Hao Y, Hwang K, Wang L, Wang L. Disease Prediction by Machine Learning Over Big Data From Healthcare Communities. IEEE Access 2017;5:8869-8879. [doi: 10.1109/access.2017.2694446]

\section{Abbreviations}

CSS: Cascading Style Sheet 
IDS: infectious disease surveillance

JSON: JavaScript Object Notation

JWT: JSON Web Token

mHealth: mobile health

NBMLHD: Nepean Blue Mountains Local Health District

NSW: New South Wales

PHU: public health unit

\author{
Edited by G Eysenbach; submitted 28.05.19; peer-reviewed by D Mogul, RB Bentvelsen, E Almeida, R Harte; comments to author \\ 30.09.19; revised version received 23.11.19; accepted 24.01.21; published 09.03.21 \\ Please cite as: \\ Ahn E, Liu N, Parekh T, Patel R, Baldacchino T, Mullavey T, Robinson A, Kim J \\ A Mobile App and Dashboard for Early Detection of Infectious Disease Outbreaks: Development Study \\ JMIR Public Health Surveill 2021;7(3):e14837 \\ URL: https://publichealth.jmir.org/2021/3/e14837 \\ doi: $10.2196 / 14837$ \\ PMID: 33687334
}

(CEuijoon Ahn, Na Liu, Tej Parekh, Ronak Patel, Tanya Baldacchino, Tracy Mullavey, Amanda Robinson, Jinman Kim. Originally published in JMIR Public Health and Surveillance (http://publichealth.jmir.org), 09.03.2021. This is an open-access article distributed under the terms of the Creative Commons Attribution License (https://creativecommons.org/licenses/by/4.0/), which permits unrestricted use, distribution, and reproduction in any medium, provided the original work, first published in JMIR Public Health and Surveillance, is properly cited. The complete bibliographic information, a link to the original publication on http://publichealth.jmir.org, as well as this copyright and license information must be included. 